\title{
Thermo-Stability of Natural Products Based on Chlorophyll Species Embedded in Silica Xerogel
}

\author{
José Martínez-Mendoza1,2*, Erika Espericueta-González³, Diana Espericueta González ${ }^{3,4}$, \\ Gerardo Ortega-Zarzosa², Azdrubal Lobo Guerrero ${ }^{3,5}$ \\ ${ }^{1}$ Departamento de Físico-Matemáticas, Universidad Autónoma de San Luis Potosí, San Luis Potosí, México \\ ${ }^{2}$ Facultad de Ciencias, Universidad Autónoma de San Luis Potosí, San Luis Potosí, México \\ ${ }^{3}$ Facultad de Ingeniería, Universidad Autónoma de San Luis Potosí, San Luis Potosí, México \\ ${ }^{4}$ Doctorado Institucional de Ciencia e Ingeniería de Materiales, Universidad Autónoma de San Luis Potosí, San \\ Luis Potosí, México \\ ${ }^{5}$ Instituto de Física, Universidad Autónoma de San Luis Potosí, San Luis Potosí, México \\ Email: *flash@fciencias.uaslp.mx
}

Received 24 February 2016; accepted 17 April 2016; published 20 April 2016

Copyright (C) 2016 by authors and Scientific Research Publishing Inc.

This work is licensed under the Creative Commons Attribution International License (CC BY).

http://creativecommons.org/licenses/by/4.0/

(c) (i) Open Access

\section{Abstract}

This work studied the thermostability and the biostability of chlorophyll species obtained from an extract of spinach leaves embedded in a silica xerogel matrix. The analysis was done by monitoring the photosystem II (PSII) using fluorescence spectroscopy. Samples were prepared using the sol gel method with a molar ratio of ethanol/ $\mathrm{H}_{2} \mathrm{O} / \mathrm{TEOS}$ of $4: 11.6: 1$. Then, silica xerogel matrix was loaded with an extract of spinach leaves, obtained in dark conditions. The measurement of the fluorescence spectra was done at selected temperatures to the corresponding non-physiological regimen. Results indicate that the PSII band position remains unchanged when heat treatment temperature increases up $200^{\circ} \mathrm{C}$. For temperatures above $100^{\circ} \mathrm{C}$, the fluorescence intensity diminishes linearly when the temperature increases. The photosystem II embedded in silica xerogel matrix is decomposed at temperatures above $200^{\circ} \mathrm{C}$.

\section{Keywords}

Chlorophyll, Structure, Biostability, Sol-Gel

\section{Introduction}

Organic complexes such as the metalloporphyrins have recently received much interest due to their prominent "Corresponding author.

How to cite this paper: Martínez-Mendoza, J., Espericueta-González, E., González, D.E., Ortega-Zarzosa, G. and Guerrero, A.L. (2016) Thermo-Stability of Natural Products Based on Chlorophyll Species Embedded in Silica Xerogel. American Journal of Analytical Chemistry, 7, 356-362. http://dx.doi.org/10.4236/ajac.2016.74034 
role in natural processes and a great deal of attention has been put in the broad range of physical and chemical properties of these complexes that result in them having a main role in biological systems, solar energy conversion, photonics and catalysis [1]. A novel idea is to take advantage of these properties and prepare unique materials based on extract of plants that will contain organic complexes such as the chlorophylls and other carotenoid pigments, which will permit to design optical and electro-optical devices based on the encapsulation of these biomolecules with asilica cover [2].

Immobilization of organic species using an inorganic medium may be useful to design energy conversion devices [3]. However, it is necessary to study the structural evolution of the organic compounds when they have been embedded into a silica xerogel matrix, as well as their interaction with an inorganic matrix when they are subjected to a heat treatment, all these in order to understand the optical behavior in function of the structural changes, both in the matrix and the organic compound.

The Photosystem PSII is a large and supramolecular pigment-protein embedded in the thylakoid membranes of green plants. It is constituted of at least 25 different types of protein sub-units. The thylakoid membrane is believed to be the most thermolabile membrane of the plant cell. It is then natural to consider the chlorophyll fluorescence as a very sensitive tool for monitoring the state of the photosynthetic apparatus at any certain time and, this particular characteristic has been subject of intensive research.

Chlorophyll is a pigment which traps the solar energy in the photosynthesis process, so that it can be used to drive the production of carbohydrates from carbon dioxide and water. During photosynthesis, the chlorophyll molecules act as an antenna system in the PSI and PSII photosystems. Once the photon has been absorbed, the energy is quickly transferred to the chloroplast, where is used to drive chemical processes. However, when chlorophyll molecules are extracted from leaves, the absorbed energy can no longer be trapped, and energy is emitted as fluorescence.

In plants, the chlorophyll molecules exist in two forms called chlorophyll $a$ and $b$. The proteins and organelles involved in the light reactions are located in and on the thylakoid membrane. This membrane is located in chloroplast. The chlorophyll is present in both photosystems (PSI, PSII). The maximum fluorescence intensity found in the PSI photosystem occurs at $735 \mathrm{~nm}$, whereas in the PSII photosystem, the maximum fluorescence takes places at $683 \mathrm{~nm}$. At room temperature, it is assumed that all variable fluorescence has its origin in the PSII photosystem which is related with the presence of chlorophyll $a$ [4] [5]. Then, by analyzing the optical behavior of the PSII photosystem, it is possible to obtain information about the bio stability of the compounds.

In green leaves the chlorophyll content begins to decompose at temperatures about $70^{\circ} \mathrm{C}$. This indicates that their non-physiological temperature is about $70^{\circ} \mathrm{C}$. Also, it has been reported that the fluorescence of chlorophyll, which was measured from leaves of barley, was raised and then decreased, when leaves were heated from room temperature to their non-physiological temperature $\left(50^{\circ} \mathrm{C}-75^{\circ} \mathrm{C}\right)$ [6]. In addition, the gradual decrement in the fluorescence is observed in a greater temperature range than $100^{\circ} \mathrm{C}$. This can be modeled as a purely physical effect [7] [8]. This behavior reflects a damage in photosystem PSII and can be used as indicator of thermostability lost [9]. The position of the emission peak decreases when green leaves are heated within temperature range from $25^{\circ} \mathrm{C}$ to $60^{\circ} \mathrm{C}$, whereas the position of the emission peak of the embedded leaves in silica remains invariant [2]. Very few works have been done about thermostability of green leaves extracts embedded in an inorganic matrix and, only few works related with biostability in terms of aging time have been reported. In particular, Manna et al. reported an aging time of three months for the photosystem PSII; in this period the fluorescence intensity remains unchanged in terms of sol-gel aging time [10]. This result contrasts with the case of barley leaves, embedded in silica matrix, where a blue shift of $10 \mathrm{~nm}$ of the red emission peak was observed, when aging time was of 12 months [2]. This blue shift also was observed in samples of ortho-amino-substituted porphyrin $\mathrm{H}_{2} \mathrm{~T}\left(\mathrm{o}-\mathrm{NH}_{2}\right) \mathrm{PP}$, embedded in $\mathrm{SiO}_{2}$ matrix [11]. This work reports biostability and thermostability of green leaves extract embedded in a silica matrix prepared by sol-gel method. As part of the extracted components of the leaves the chlorophyll $a$ is included. Then, it was monitored the photosystem PSII using fluorescence spectroscopy in samples with heat-treatment and in samples without heat treatment, but aged up to 36 months.

\section{Experimental Method}

The sol-gel method was used in order to obtain organic composites based on extract of leaves and embedded in a silica matrix. TEOS, deionized water, ethanol and pigment extract of spinach leaves were used as raw materials.

In order to extract the compound of leaves a crude extraction from frozen leaves in dark conditions is used, 
the leaves were washed with water then, they were grinded and mixed with ethanol. The obtained leaves extract mixed with ethanol was centrifuged at $3000 \mathrm{rpm}$ for $5 \mathrm{~min}$ and finally filtered with a Whatmanfilter \#1.

The molar ratio used between ethanol and TEOS was 4:1 and between water and TEOS was 11:1. These ratios proved to give good quality of the silica coating, and match the higher ratio between water and TEOS required to enhance the hydrolysis and ensure a close amorphous structure for the as-prepared silica powder [12].

The TEOS was dissolved in ethanol using a magnetic stirring during $15 \mathrm{~min}$. Then, the previously obtained suspension of pigments and water was added to the solution of ethanol with TEOS to form the starting material, and after of $48 \mathrm{~h}$, soft pieces of gel were obtained. Those pieces were ground to form a fine powder which was heated during $30 \mathrm{~min}$ in a Lindberg oven under atmospheric pressure at $100^{\circ} \mathrm{C}$ and $250^{\circ} \mathrm{C}$.

The measurements of the emission spectra were carried out in a fluorescence spectrometer Ocean Optics Inc. Model SF2000, using a reflectance diffused $45^{\circ}$ with a double fiber optic component excited with an Omnicrome argon ion laser of $532 \mathrm{~nm}$ and filter HNF-532-1.0 in order to obtain the fluorescence contribution due to the photosystem PSII and the behavior under heat treatment.DTA measurements were carried out in a TA Instruments system, model Q600 at constant rate of $10^{\circ} \mathrm{C} / \mathrm{min}$, inside DTA analyzer in nitrogen atmosphere up to $400^{\circ} \mathrm{C}$.

\section{Results}

Intensity of the chlorophyll fluorescence obtained from leaves, presents an increment when temperature increases, and then decreases when leaves heat up to their non-physiological temperature, which is about of $70^{\circ} \mathrm{C}$, this gradual decrement of the fluorescence has been modeled as a physical effect and can be seen within a much larger temperature range from $100^{\circ} \mathrm{C}$ [7] [8]. Moreover, one main effect when extract of leaves is embedded in a silica matrix, is that the fluorescence transients of the photosystem PSII are not present, and when the doped glass is illuminated, the only fluorescence phase is the steady state phase.

Figure 1 shows the measurements of fluorescence spectra obtained from extracts of spinach leaves embedded in silica glass for samples with and without heat treatment, extract of the leaves was done in dark conditions at room temperature. It is observed that the region which presents the photosynthetic activity is between $620 \mathrm{~nm}$ to $750 \mathrm{~nm}$. In this case, the fluorescence intensity is related with the PSII photosystem of the chlorophyll species. From Figure 1, it is observed that the fluorescence intensity increases in samples heat treated at $100^{\circ} \mathrm{C}$, then decreases when heat treatment is higher. This figure shows a typical fluorescence spectrum of the chlorophyll a, related to the PSI and PSII photosystems. The maximum intensities correspond to the excitation energy transfer toward the two PSI and PSII. The peak observed at $675 \mathrm{~nm}$ is related to the PSII photosystem, and the observed

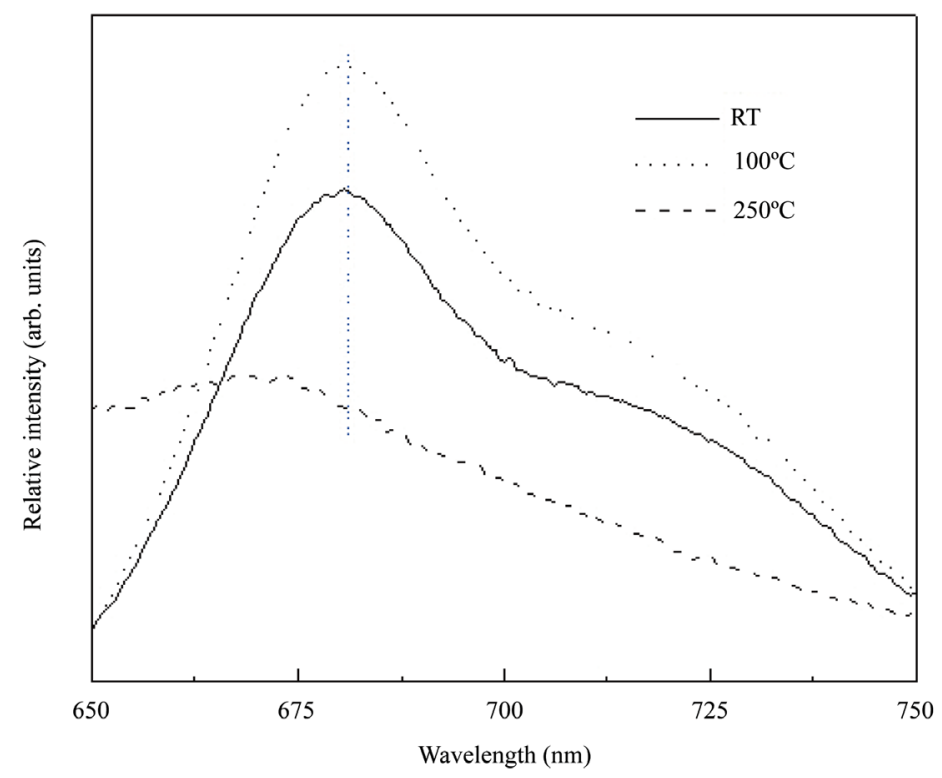

Figure 1. Fluorescence spectra of extracts spinach leaves embedded in silica xerogel matrix and at different temperatures. 
at $710 \mathrm{~nm}$ and $730 \mathrm{~nm}$ corresponds to the PSI photosystem. The presence of chlorophyll a is related with the PSII photosystem, instead The photosystem PSI is related with the superposition of the fluorescence bands of chlorophyll a and $b$, at 730 and $710 \mathrm{~nm}$, respectively.

The fluorescence related with the photosystem PSII is the parameter used as indicative of chlorophyll stability, and their variation indicates degradation or denaturation of the species. As is observed in Figure 1, the position of the fluorescence band for PSII remains unchanged and only variations in intensity is observed at temperatures corresponding to the non-physiological range. The maximum position of fluorescence peak obtained from green leaves decreases and shifts to blue when the temperature goes up from $25^{\circ} \mathrm{C}$ to $60^{\circ} \mathrm{C}$, whereas when these leaves were embedded in glass, the position of the fluorescence spectra remained unchanged at temperatures near to $200^{\circ} \mathrm{C}$. For the sample heated at $250^{\circ} \mathrm{C}$, a blue shift of ten nanometers is observed in the band corresponding to the PSII. Thus, at this temperature, the sample presents a fraction of decomposition of the chlorophyll a in the PSII photosystem. Mainly, takes place a primary conversion of the chlorophyll in proteins as phaeophytene [11] [13].

The fluorescence spectra were measured at the non-physiological regimes, for temperatures above $100^{\circ} \mathrm{C}$, when temperature increases the fluorescence intensity diminishes linearly to reach a minimum value. Figure 1 shows that photosystem II of extract leave embedded in the silica xerogel matrix begin to decomposed at higher temperatures than $200^{\circ} \mathrm{C}$, which indicates that silica matrix provides thermostability.

The peak of the sample heat treated at $100^{\circ} \mathrm{C}$ is centered at the same position that sample without heat treatment, which indicates that the chlorophyll not decomposes or in other words, does not occur a denaturing of PSII photosystem. In this manner, the sample heat treated at $250^{\circ} \mathrm{C}$, still has fluorescence signal in the band located at $675 \mathrm{~nm}$, indicating PSII activity, thus the chlorophyll a molecules remain structurally intact. The chlorophyll decomposition is in process and the band center is located at $666 \mathrm{~nm}$, then there is a blue shift, which indicates a chlorophyll conversion to phaeophytinin course, beginning to form a band at $580 \mathrm{~nm}$.

Then, when leaves extract is embedded in a silica matrix, the chlorophyll decomposition is retarded and a minimal transformation in phaeophytinor some other protein specie takes place. The complete denaturation of the PSII photosystem in samples heated at higher temperature leads to the formation of quenching centers [2], thus chlorophyll embedded in a silica matrix also exhibit biostability.

This result is corroborated with an DTA analysis, by preparing rich in chlorophyll powders, and put through heating at constant rate $10^{\circ} \mathrm{C} / \mathrm{min}$ in nitrogen atmosphere. Figure 2 shows endothermic peaks at 99, 225 and

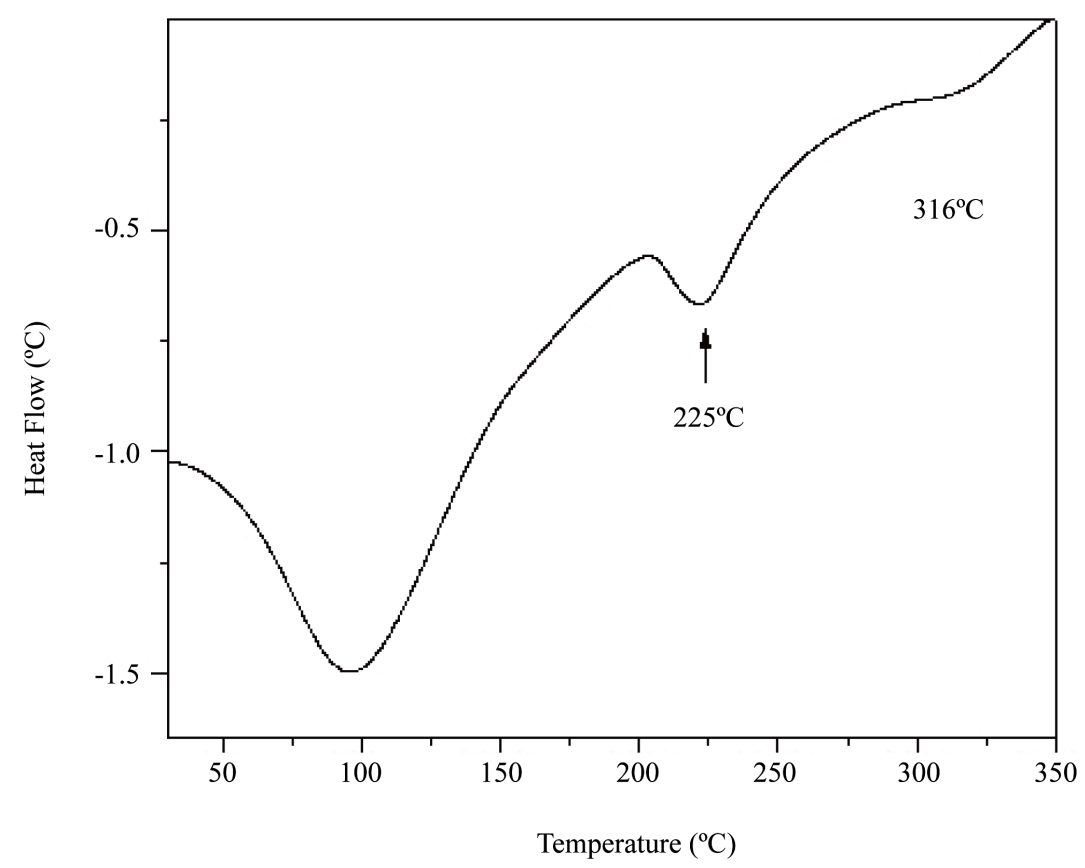

Figure 2. DTA curve of the extract of spinach leaves embedded in a silica xerogel matrix heat treated at nitrogen atmosphere. 
$316^{\circ} \mathrm{C}$. After $400^{\circ} \mathrm{C}$, occurs an endothermic process due to decomposition of chlorophyll species (not showed), and structural evolution of the matrix. The DTA peak at $99^{\circ} \mathrm{C}$ correspond to partial water elimination, and chlorophyll species begin decompose at temperatures around $225^{\circ} \mathrm{C}$, which gives rise to the formation of organic compounds, such protein complexes, and stable fluorescent organic species. At $316^{\circ} \mathrm{C}$ is presented another decomposition process of the photosystem PSII, and diminishes the fluorescence band related to the chlorophyll species whereas is observed an increment of the fluorescence band situated at $580 \mathrm{~nm}$, as discussed in previous works [13] [14]. In this sense, the fluorescence decreases slowly when the leaves were embedded in silica glass, in contrast with the green leaves without imbibing, the denaturation of organic species carries out in a slow way. This situation are due that the photoprotective mechanism in which the non-photochemical quenching, such the high-energy-state quenching $(\mathrm{qE})$, is activated in the composites formation, and it is stimulated the interaction between inorganic matrix and the extract of leaves. In the case for leaves embedded in glass, we observed for high temperatures (not discussed here) that fluorescence aggregates are formed. This is an important mechanism to form fluorescence glass.

The thermal behavior changes according with the variation of the preparation parameters, Figure 3 shows fluorescence spectra of extract leaves obtained in light conditions without heat treatment and calcined at $200^{\circ} \mathrm{C}$. When extraction of chlorophyll species is done under light condition, maintaining the other parameters unchanged, the PSII fluorescence intensity has a great decrement and occurs decomposition of the chlorophyll species, the band located at about $580 \mathrm{~nm}$ increases, which is associated to aggregation of pigments indicating the decomposition of the photosystem PSII.

Figure 4 shows there is no significant change of fluorescence of chlorophyll entrapped in silica xerogel up to 36 months kept in light and weather conditions. This reveals that no change in chlorophyll structure, thus the PSII photosystem remains structurally unchanged in the silica, over a very long period of time. In particular, the maximum position of fluorescence of the PSII not change in terms of the sol-gel aging time.

In general, the biostability is presented in organic compounds incorporated into silica xerogel matrix. In Figure 5 is shown infrared absorption spectrum in the range from 1000 to $1400 \mathrm{~cm}^{-1}$, where the main stretching band of vibration modes of the Si-O-Si bonds is observed and the peak located at $1370 \mathrm{~cm}^{-1}$, which is indicated by an arrow, it is assumed as $\pi$-d interaction between pyrrol type ring with the empty d orbital of silicon in the silica gel matrix, which stabilizes the organic species in silica gel, accord with J. S. Manna [10].

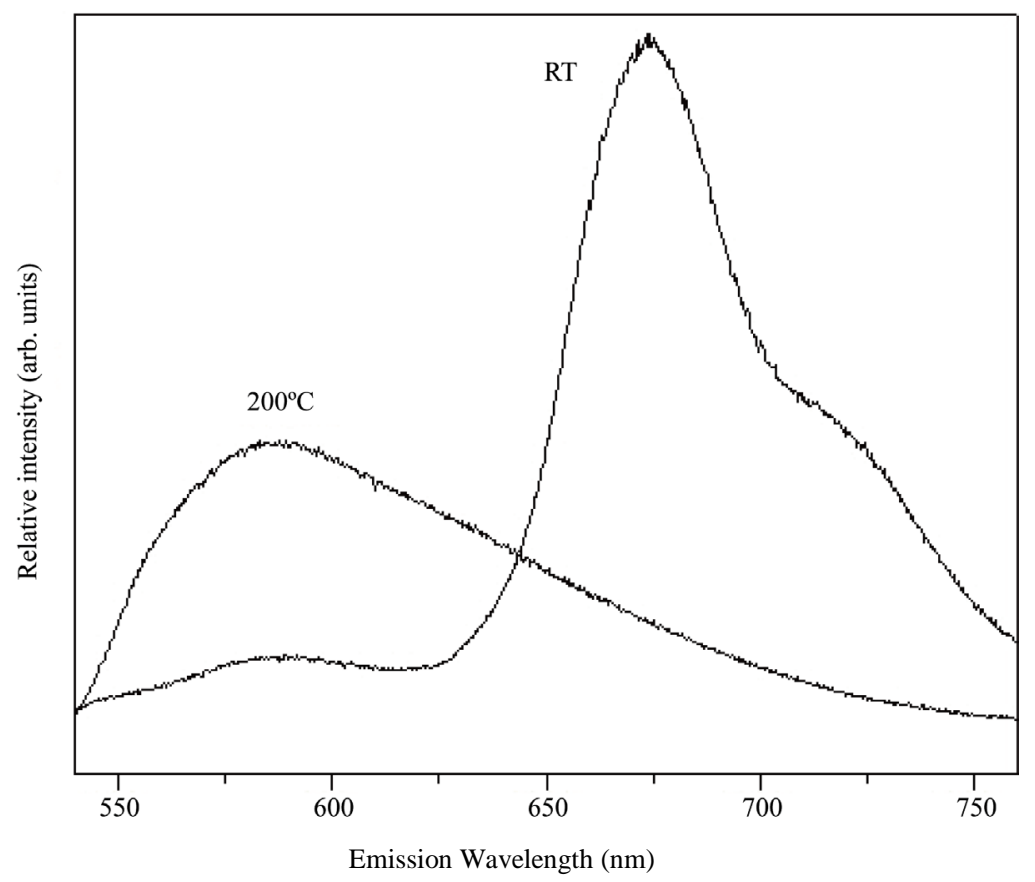

Figure 3. Fluorescent emission spectra of spinach leaves extracted in light conditions and embedded in silica xerogel matrix without heat treatment (RT) and calcined at $200^{\circ} \mathrm{C}$. 


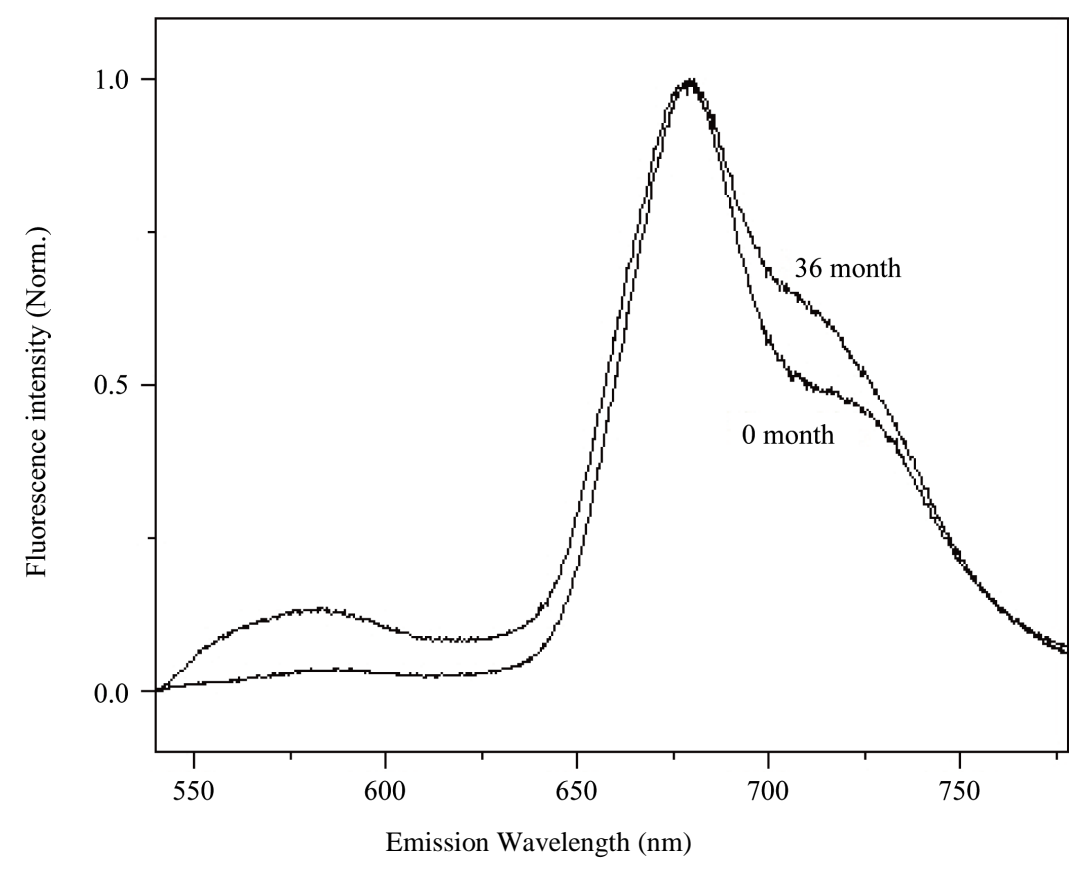

Figure 4. Fluorescent emission spectra of spinach leaves embedded in silica xerogel matrix without heat treatment, measured after gelling and after 36 months.

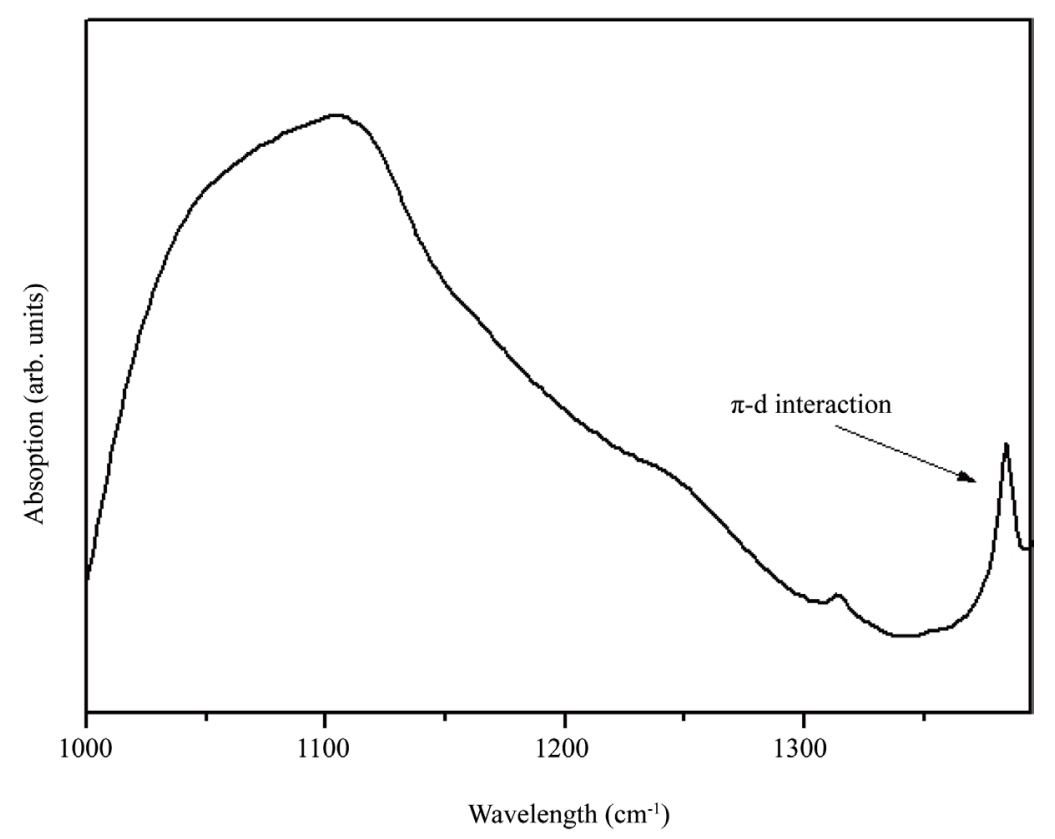

Figure 5. Infrared absorption spectrum of spinach leaves embedded in silica xerogel matrix without heat treatment.

\section{Conclusion}

In conclusion, the obtained PSII photosystem from extracts of spinach leaves and embedded in the silica xerogel matrix, presents high thermostability, high biostability, and remains bioactive over a very long period of time. The presence of unaltered chlorophyll, in the last studied case, is at temperatures above $200^{\circ} \mathrm{C}$, which is higher than the former case. Thus, the chlorophyll molecules entrapped in silica xerogel remain bioactive over a long period of time and at relatively high temperature. This indicates a higher PSII thermostability for leaves embed- 
ded in xerogel matrix than in the green leaves. Another difference between green leaves and leaves embedded in glass is the position of the emission maximum, whereas the position of the emission maximum decreases for the green leaves during heating within temperature range from $25^{\circ} \mathrm{C}$ to $60^{\circ} \mathrm{C}$, and the position of the emission maximum for leaves embedded in glass matrix remains constant.

\section{References}

[1] Ghosh, A., Selvamani, T., Amilan, D., Das, A. and Mukhopadhyay, I. (2007) Generation of Nanostructures by the Aggregation of Porphyrin Derivatives with Long Alkane Chain in Mix-Solvent. Journal of Nanomaterials, 2007, Article ID: 47234. http://dx.doi.org/10.1155/2007/47234

[2] Vázquez-Durán, A., Araujo-Andrade, C., Martínez-Castañón, G., Ortega-Zarzosa, G., Ruiz, F. and Martínez, J.R. (2006) Spectral Characterization of Chlorophyll Fluorescence in Extract of Barley Leaves Embedded in Silica Xerogel Matrix. Journal of Sol-Gel Science and Technology, 39, 223-227. http://dx.doi.org/10.1007/s10971-006-7877-x

[3] Furukawa, H., Inoue, N., Watanabe, T. and Kuroda, K. (2005) Energy Transfer between Chlorophyll Derivatives in Silica Mesostructured Films and Photocurrent Generation. Langmuir, 21, 3992-3997. http://dx.doi.org/10.1021/la047845z

[4] Briantais, J.M., Vernotte, C., Krause, G.H. and Weiss, E. (1986) Light Emission by Plants and Bacteria. Academic Press, New York.

[5] Baker, N.R. and Webber, A.N. (1987) Interactions between Photosystems. Advances in Botanical Research, 13, 1-66. http://dx.doi.org/10.1016/S0065-2296(08)60340-7

[6] Ilík, P., Kouřil, R., Fiala, J., Nauš, J. and Vácha, F. (2000) Spectral Characterization of Chlorophyll Fluorescence in Barley Leaves during Linear Heating: Analysis of High-Temperature Fluorescence Rise around $60^{\circ} \mathrm{C}$. Journal of Photochemistry and Photobiology B: Biology, 59, 103-114. http://dx.doi.org/10.1016/S1011-1344(00)00146-9

[7] Pospíšil, P. and Nauš, J. (1998) Theoretical Simulation of Temperature Induced Increase of Quantum Yield of Minimum Chlorophyll Fluorescence $\Phi \mathrm{F}(0)$. Journal of Theoretical Biology, 193, 125-130. http://dx.doi.org/10.1006/jtbi.1998.0691

[8] Pospíšil, P., Skotnica, J. and Nauš, J. (1998) Low and High Temperature Dependence of Minimum F0 and Maximum FM Chlorophyll Fluorescence in Vivo. Biochimica et Biophysica Acta (BBA)—Bioenergetics, 1363, 95-99. http://dx.doi.org/10.1016/S0005-2728(97)00095-9

[9] Schreiber, U. and Berry, J.A. (1977) Heat-Induced Changes of Chlorophyll Fluorescence in Intact Leaves Correlated with Damage of the Photosynthetic Apparatus. Planta, 136, 233-238. http://dx.doi.org/10.1007/BF00385990

[10] Manna, J.S., Basu, S., Mitra, M.K., Mukherjee, S. and Das, G.Ch. (2009) Study on the Biostability of Chlorophyll a Entrapped in Silica Gel Nanomatrix. Journal of Materials Science: Materials in Electronics, 20, 1068-1072. http://dx.doi.org/10.1007/s10854-008-9827-6

[11] García Sánchez, M.A., Tello, S.R., Sosa, R. and Campero, A. (2006) Fluorescent Porphyrins Trapped in Monolithic $\mathrm{SiO}_{2}$ Gels. Journal of Sol-Gel Science and Technology, 37, 93-97. http://dx.doi.org/10.1007/s10971-006-6425-z

[12] Martínez, J.R., Ruiz, F., Vorobiev, Y.V., Pérez-Robles, F. and González-Hernández, J. (1998) Infrared Spectroscopy Analysis of the Local Atomic Structure in Silica Prepared by Sol-Gel. Journal of Chemical Physics, 109, 7511. http://dx.doi.org/10.1063/1.477374

[13] Espericueta, E., Martínez, J.R., Ortega-Zarzosa, G. and González-Hernández, J. (2010) Blue-Shifted Fluorescence Spectrum in Silica Xerogels with Incorporation of Extract’s Leaves. Journal of Sol-Gel Science and Technology, 56, 114-120. http://dx.doi.org/10.1007/s10971-010-2283-9

[14] Martínez, J.R., Espericueta, E. and Ortega-Zarzosa, G. (2011) Effect of Aging on Chlorophyll Species Embedded in Silica Xerogels Matrix. New Journal of Glass and Ceramics, 1, 7-12. http://dx.doi.org/10.4236/njgc.2011.11002 